\title{
Da história das disciplinas ao mundo do ensino: entrevista com Ivor Goodson
}

From history of disciplines to learning world: interview with Ivor Goodson*

Educação em Revista: O sr. é conhecido no Brasil na área de História das Disciplinas. Poderia falar um pouco sobre o seu trabalho nesta área e os principais resultados dele?

Ivor Goodson: É difícil saber quais os principais resultados. O trabalho começou como uma forma de entender de que modo as disciplinas do currículo escolar afetavam a vida dos alunos e professores. Eu lecionava algumas disciplinas bastante incomuns - uma delas se chamava Estudos Ambientais - que não eram consideradas disciplinas propriamente ditas. Então eu queria descobrir de onde tinham vindo as disciplinas propriamente ditas, como a biologia, e porque elas pareciam não ter muito interesse para os estudantes. Quais eram os motivos políticos, sociais e históricos daquele fato? Então comecei a analisar o histórico de uma série de disciplinas e também o contexto da entrada de novas disciplinas no currículo escolar, já que a nova disciplina era Estudos Ambientais e as tradicionais lutavam contra ela. Ficou claro que havia uma política governando as disciplinas do currículo escolar. Então o que eu acabei fazendo foi tentar ensinar aos professores e pesquisadores que o currículo é um processo político e social e que não é possível entendê-lo como puro conhecimento, conhecimento descontextualizado, conhecimento social. Trata-se de um conhecimento politicamente estruturado, nem sempre de maneira conservadora, negativa. Eu não tenho uma atitude esquerdista, completamente determinista. Às vezes, a política é boa, às vezes é má, mas é sempre política. O que devemos estabelecer é que tipo

Realizada durante $29^{a}$ Reunião Anual da ANPEd (15 a 18 de outubro de 2006, Caxambu/MG). 
de política está por trás das disciplinas escolares e do conhecimento delas, bem como que impacto tudo isso tem na escola, no professor e nos alunos.

ER: Mas e as principais conquistas?

IG: A conquista é estar sentado e falando aqui no Brasil. Eu sei que os estudiosos brasileiros já usaram este trabalho em suas próprias pesquisas e no seu trabalho com os alunos. Minha esperança é que ele seja difundido no âmbito do conhecimento desse processo social e político que será compartilhado também com os professores. Acho que se isso estiver funcionando - e o fato de que meus livros sobre o tema já se encontram em dezessete línguas significa que eles têm alguma relevância para a maioria dos países - pouco a pouco, os estudiosos vão se dar conta do trabalho. A questão é que eu não conheço o Brasil, mas vocês conhecem. Vocês podem usar a metodologia e a abordagem para comunicar os saberes sociopolíticos aos pesquisadores e educadores do seu país. E, no meu entender, esta é a grande conquista, porém, é também uma conquista no que tange ao método.

ER: Alguns estudiosos da História da Educação criticam a história das disciplinas, dizendo que esta não é a história real da educação. Isto acontece em outros países? Como o sr. responde a essa crítica?

IG: A resposta é que isto acontece na maioria dos países, porque a própria história da educação faz parte de um processo sociopolítico e, sendo assim, ela se defende contra novos tipos de história. A resposta, seja no Canadá, na Inglaterra ou nos Estados Unidos, países onde eu já trabalhei, é que a história da educação como disciplina está enfrentando problemas políticos e não está sobrevivendo bem em nenhum país. Não sei como está a situação no Brasil, mas ela está em declínio na maioria dos países. Portanto, a maneira mais inteligente de abrir a discussão - é assim que eu faço na Inglaterra - é dizer: o ensino da história está fracassando, está perdendo público porque não é prático o suficiente para o mundo dos professores. Sendo assim, por que não começar a abraçar a história do currículo, que vai trazê-la de volta ao mundo do professor? Desse modo, os historiadores da educação começaram a aceitar que a história do currículo era uma parte importante e uma parte que eles também poderiam tratar, em vez de simplesmente dizer: "Não, isto não é história". Isto seria suicídio para eles. É uma estupidez os historiadores afirmarem isto, porque, ao fazerem, estariam contribuindo para o seu próprio fracasso. 
ER: O trabalho que o sr. fez inclui a legitimação da idéia da ciência no currículo, que é muito bem-vinda.

IG: Isto é o mais interessante. Acabo de falar com um colega de Portugal e, quando eu voltar, vou falar para professores de ciências da educação em Madeira, Portugal. Esses professores, em minha opinião, entendem que se trata de uma questão de legitimação política. Entendem também, como os professores inteligentes de qualquer disciplina, que o caminho para o sucesso desta é entender o processo sociopolítico do qual estou falando. Portanto, os professores inteligentes, como os de biologia, de ciências, entendem isto. Porém, os que não são inteligentes não entendem. Assim, se vocês não atentarem para isso, vão ter o mesmo problema. $\mathrm{O}$ que nós desejamos é que os professores de algumas das disciplinas mais interessantes também compreendam o processo. Vocês sabem, a biologia não tem problemas, já está legitimada. Então, seus docentes ficam felizes em compreender o processo que a mantém. Entender o processo é a maneira mais inteligente de se trabalhar. Os professores de ciências sempre foram fantásticos. Desde o primeiro dia, o trabalho sempre foi bem-vindo pelos professores de ciências. O mesmo acontece no Brasil, em Portugal e na Espanha. Outros educadores têm dúvidas sobre isto porque às vezes eles questionam a própria legitimidade do que ensinam.

$\boldsymbol{E R}$ : Se o sr. fosse explicar em poucas palavras a diferença entre a metodologia histórica tradicional e seus próprios métodos, o que diria?

IG: É uma combinação de um trabalho histórico tradicional pelo qual você lê documentos e arquivos e volta ao passado nos textos escritos, combinando tudo isso com uma abordagem sociológica que diz: "Vamos fazer entrevistas e histórias de vida e vamos entrevistar professores sobre a história de suas disciplinas." Então você combina o histórico com o humano, o que é uma combinação incomum. Como vocês sabem, eu combino história do currículo com história de vida. Considero que é uma combinação muito significativa, o tipo de combinação que vou usar cada vez mais, porque tem conexão com o mundo do professor. Esta é uma parte vital do nosso estudo. Senão, seria mera pesquisa, seria apenas fazer aquelas "coisinhas espertas" que fazemos em nossas conferências sobre pesquisa educacional, ou seja, trocar idéias uns com os outros. É aí que está o grande perigo das pesquisas na área da educação, ou seja, especialistas e pesquisadores conversando entre si, sem jamais se conectarem com a realidade: os debatedores estão aqui e a escola está lá 
embaixo, mas eles não interagem. O objetivo da história do currículo e da história de vida é tornar essa conexão essencial. A própria metodologia insiste que o pesquisador converse com os professores, pense neles e entre em contato com eles, respeitando-os, porque não é possível trabalhar de outra forma. Afinal, eles são as fontes. Então, uma vez que você faz deles a sua fonte, precisa respeitá-los imediatamente como seus iguais. Isso é algo que os pesquisadores nem sempre fazem, como todos sabemos. Às vezes eles simplesmente usam o professor como um fantoche para as suas próprias teorias. "Os professores disseram isto, os professores disseram aquilo", mas eles não ouvem de fato o professor. Este método exige que você ouça de perto os professores, e esta é a grande conquista dele.

ER: Como este tipo de pesquisa nos ajuda a entender o currículo escolar atual? Por exemplo, a disciplinarização do currículo escolar, a ênfase em determinadas disciplinas, como matemática e ciências.

IG: Se você usar a palavra-chave, o alvo é alcançar a hegemonia, atingir a primazia. E, como vocês sabem, os partidos políticos vão defender seus governos da mesma maneira que o Lula está defendendo o seu governo contra a oposição. As disciplinas fazem a mesma coisa. E nem sempre isto está necessariamente ligado ao interesse da educação ou da legitimidade; trata-se da defesa de uma entidade política, uma coalizão em prol de uma disciplina. Portanto, a questão é entender como essa hegemonia é mantida, mas também questioná-la, verificar se, de fato, é bom para os alunos e professores o ensino de uma disciplina desse tipo. Vocês todos devem estar familiarizados com as três tradições de uma disciplina: acadêmica, pedagógica e utilitária. Eu digo que cada disciplina é uma união de tradições diferentes. $\mathrm{E}$ a tradição acadêmica tende a vencer. Mas nem sempre ela é interessante para os alunos, e essa batalha, dentro da disciplina, é também uma parte essencial para se entender. Portanto, a hegemonia da disciplina e a batalha dentro da disciplina são ambas importantes: batalhas políticas entre as disciplinas e também batalhas políticas no interior das disciplinas.

ER: O sr. não está mais trabalhando com a história das disciplinas. Como o sr. conecta a história das disciplinas com a sua pesquisa atual?

IG: Estou em busca da ligação que acabei de descrever. Ou seja, como eu trabalhei com a história da maioria das disciplinas, e acho que entendo grande parte das mesmas, tentei escrever livros sobre a história dessas 
disciplinas. Escrevi vinte livros sobre isso. Acabei considerando que, de certa forma, para mim já era suficiente. Outros pesquisadores estão retomando esse trabalho no Brasil. Assim, o que eu estou tentando fazer é buscar essa conexão - que significa para a obra de vida do professor? Que significa para a sua vida pessoal lecionar uma disciplina? Que significa, de fato, o conhecimento da disciplina para o professor na sala de aula? Que significa lecionar uma disciplina de uma certa maneira, em termos do interesse dos alunos, já que o padrão da disciplina é também um padrão de priorização, de priorizar socialmente algumas crianças às custas de outras? Então, como disse anteriormente, disciplinas de um tipo específico mistificam o padrão da reprodução social, porque algumas crianças se saem bem e outras fracassam. Portanto, penetrar no mundo do professor e observar como ele leciona a disciplina, como alguns alunos são bemsucedidos e outros fracassam, faz parte do processo de seguir aquela linha de pesquisa que se aprofunda no mundo do professor e procura conectar tal tipo de pesquisa ao mundo da escola. A minha preocupação é que, quando nos sentamos à beira da piscina e trocamos idéias com outros pesquisadores, é muito fácil esquecer a escola, é muito fácil esquecer as crianças e é muito fácil esquecer os professores, porque não estamos no contexto escolar, estamos à beira da piscina, conversando uns com os outros. Temos que nos lembrar do nosso dia-a-dia: não faz sentido estarmos aqui se não respeitarmos as escolas. Seremos meros parasitas acadêmicos, estaremos fazendo pesquisa porque gostamos de pesquisa, mas será sempre pesquisa, nunca será ação social, de forma nenhuma. Por isso, no meu entender, precisamos sempre retornar à escola, ao professor, ao mundo do ensino. Se não, estaremos entregues à pesquisa educacional e não seremos ativistas educacionais.

ER: Algumas pesquisas que investigam a vida do professor o fazem por meio da narrativa do professor. Como o sr. relaciona o seu trabalho com este tipo de abordagem?

IG: Eu tenho algumas importantes ressalvas quanto à mera narrativa, porque considero que simplesmente tomar as histórias dos professores é deixá-los no seu ponto de partida, é deixá-los com suas percepções. A idéia principal de se fazer históricos de vida é compartilhar, nas entrevistas, diferentes cosmovisões. Se estou fazendo a entrevista e você é o professor, quero muito ouvir o seu ponto de vista, mas quero também que você compartilhe o meu ponto de vista. É, portanto, uma interação. Já a história 
de vida sugere: “Tudo bem. Esta é a sua narrativa e este é o ponto de partida da investigação, mas eu também quero conhecer a história da sua disciplina, a história da sua escola." As histórias de vida são narrativas, mas podemos recorrer também a fontes documentais, a outras entrevistas, a histórias da educação, triangulando as narrativas, produzindo-as, tornando-as histórias de vida. Na realidade eu me oponho à narrativa pura. A narrativa é, sim, o ponto de partida, mas a narrativa como o ponto final deixa as pessoas exatamente onde elas estavam, o que faz dela uma metodologia politicamente conservadora. Assim, eu sou fortemente contra. Eu costumo utilizar bastante as narrativas, mas apenas como ponto de partida. Quero ir além e situar a narrativa em seu contexto histórico e social. É o que chamo de " $A$ história de vida" e o meu novo trabalho trata disso. Meu novo livro se chama Narrativa curricular e futuro social e vou falar sobre o tema amanhã. ${ }^{1}$

Tradução: Charles Bacon

Revisão de tradução: Antonio Flavio Barbosa Moreira

Recebido em: 10/12/06

Aprovado em: 03/03/07

1 Referência à mesa-redonda "Currículo e história: entrelaçamentos metodológicos", realizada em 18 de outubro de 2006, na 29a Reunião Anual da ANPEd. 